\title{
Exploration of an Effective Method for the Step-by-Step Presentation of Case Information to Guide Grade 4 Medical Students to Develop Clinical Reasoning Skills
}

\author{
Simin Huang ${ }^{1}$, Jing Yang ${ }^{1}$, Feifei Wang ${ }^{1}$, Jun Guo $^{1, *} \&$ Shengming Liu ${ }^{1, *}$ \\ ${ }^{1}$ Department of Internal Medicine, the First Affiliated Hospital of Jinan University, Guangzhou, 510630, China \\ *Correspondence: Jun Guo, Department of Internal Medicine, the First Affiliated Hospital of Jinan University, \\ Guangzhou, 510630, China. Tel: 1-306-885-0877. E-mail: dr.guojun@163.com and Sheng-ming Liu, Department of \\ Internal Medicine, the First Affiliated Hospital of Jinan University, Guangzhou, 510630, China. Tel: 1-339-269-1968. \\ E-mail: tlsm@jnu.edu.cn
}

Received: November 20, 2020

Accepted: January 18, 2021 Online Published: February 15, 2021

doi:10.5430/jct.v10n1p36

URL: https://doi.org/10.5430/jct.v10n1p36

\begin{abstract}
Clinical reasoning ability is an important competence for a clinician to have. Undergraduate study is a crucial period to strengthen medical students' clinical reasoning skills. The aim of this study was to explore an effective method for guiding students to improve clinical reasoning skills via a step-by-step presentation of case information. The study was conducted among grade 2015 clinical medicine major students who were studying internal medicine. On the basis of the theoretical study and practical training, a method for the step-by-step presentation of case information was designed and implemented to strengthen students' clinical reasoning skills. Each case was divided into four modules. Module one focused on inquiry, module two focused on physical examination, module three focused on laboratory tests and module four focused on diagnosis and treatment. Four modules were sent to students in turn as homework. The teacher corrected their answers and feedback was individually given. A questionnaire was conducted at the end of semester to assess the effect. The questionnaire revealed that students were satisfied with this training mode. They thought the mode was helpful for improving clinical reasoning ability and consolidating the basic skills such as history taking and physical examination. In conclusion, this effective method provides a training pattern for developing clinical reasoning skills of medical students. Through the process of analysing clinical cases, students are guided to become familiar with the procedures of solving clinical problems from gathering medical information to establishing diagnosis and treatment plans. It helps students to establish a scientific clinical reasoning mode.
\end{abstract}

Keywords: clinical reasoning, undergraduate medical education, medical students, clinical course

\section{Introduction}

Diagnosis-making is a basic practice for any doctor. It is a process in which doctors draw conclusions by making analyses, summaries, judgement and reasoning based on the information acquired through inquiry, physical examination and auxiliary examination. A diagnosis is the foundation and precondition for the treatment of a disease. Therefore, based on the combination of medical knowledge and experience, clinicians must establish a correct diagnosis. In the process of making correct diagnosis and treatment, an important ability is applied, that is clinical reasoning.

Clinical reasoning is considered to be the cornerstone and main component of a doctor's clinical abilities (Audétat et al., 2012). It refers to the process by which doctors gather medical information and make diagnosis and treatment plans (Daly, 2018; Dong et al., 2015; Elvén, Hochwälder, Dean \& Söderlund 2019; Shin, 2019). Clinical reasoning includes diagnostic reasoning and therapeutic reasoning (McBee et al., 2015). This process includes the application and integration of theoretical knowledge, clinical experience, critical thinking skills and reflection. Some scholars believe that misdiagnosis is associated with defects in clinical reasoning (Berge \& Mamede 2013). So, we usually say that "a correct diagnosis and treatment relies on a correct clinical reasoning".

There are many studies on clinical reasoning, ranging from the principles of reasoning to the methods for developing 
reasoning ability and evaluating its effectiveness. Among these studies, many focus on the development and evaluation of medical students' reasoning skills. For medical students, developing clinical reasoning is very important for their future careers (Deng \& Liu 2015; Goldmann, Middeke, Schuelper, Dehl \& Raupach 2017). But clinical reasoning skill is not innate ability, it must be taught and accumulated in medical education. A survey from the United States found that students received an average of 6.4 hours of clinical reasoning training at school (Rencic, Trowbridge, Fagan, Szauter \& Durning 2017). This result indicated that students do not have enough time to receive clinical reasoning ability training at university. Actually, before learning to diagnose, medical students have already studied various medical foundation courses, obtained theoretical knowledge and practiced skills of inquiry and physical examination. These are particularly important for clinical diagnosis, but such knowledge and skills alone are insufficient. Medical students must learn and apply the skills of clinical reasoning to diagnose and treat diseases. They must be instructed on how to apply such knowledge and skills with scientific reasoning in making diagnosis. Only by doing so can such knowledge and skills truly work.

How to improve clinical reasoning skills in medical students is an important topic in many countries. Monrouxe et al. believe educational interventions are needed to develop the clinical reasoning skills in medical students (Monrouxe et al., 2017). Although many scholars have explored this field, there is still no unified model and method (Audétat et al., 2012). Current methods for teaching and developing clinical reasoning include case-based learning and small group discussion (Rencic, Trowbridge, Fagan, Szauter \& Durning 2017; Shimozono, Takahashi, Tomita, Takada \& Tanaka 2019; Sacher \& Detsky 2009; Mamede et al., 2019; Yang et al., 2014). In addition, virtual patients have been used to simulate real clinical scenes for clinical reasoning training (Botezatu, Hult \& Fors 2010; Bediang et al., 2013; Kim et al., 2018). For example, clinical reasoning training system, it is a software for training clinical reasoning ability. Students can use these scenes to train repeatedly. The reasoning process will be recorded and evaluated by the system, so as to help students establish correct clinical reasoning skills and make the learning process more efficient. Furthermore, offering courses and learning from published exercises are also methods used to train clinical reasoning (Kelekar \& Afonso 2020; Harendza, Krenz, Klinge, Wendt \& Janneck 2017; Yang et al., 2017; Musgrove, Morris, Estrada \& Kraemer 2016; Beullens, Struyf \& Damme 2005).

This study was conducted among grade 4 medical students. After studying basic medicine and diagnostics, they move on to clinical courses such as internal medicine, surgery, obstetrics and gynaecology, paediatrics. It is a crucial time for them to establish clinical reasoning. Helping students to develop scientific clinical reasoning skills is an important task for teachers. In this study, a method for the step-by-step presentation of case information was introduced to clinical medicine students to develop their clinical reasoning. On the basis of theoretical learning and practical training, case information is presented to students step by step. Through this mode of theory-practice-intensive training, we hope to find an effective method to help students to consolidate their basic clinical skills, such as doctor-patient communication, history taking and physical examination, and help them understand and master the diagnosis and treatment procedures for diseases to develop their clinical reasoning skills.

\section{Methods}

\subsection{Participants}

This study was conducted among grade 2015 students majoring in clinical medicine (six-year program) at Jinan University who were taking an internal medicine course.

\subsection{Course Arrangement}

Table 1. Internal Medicine Course Arrangement in Grade 2015

\begin{tabular}{|c|c|c|c|c|c|c|c|}
\hline \multirow{2}{*}{$\begin{array}{c}\text { Internal } \\
\text { Medicine }\end{array}$} & \multirow[t]{2}{*}{ Semester } & \multirow[t]{2}{*}{ Contents } & \multirow[t]{2}{*}{ Hours } & \multicolumn{2}{|c|}{ Theoretical part } & \multicolumn{2}{|c|}{ Practical part } \\
\hline & & & & Weeks & Teaching mode & Weeks & Teaching mode \\
\hline Part I & $\begin{array}{l}2019.3 \\
\sim 2019.7\end{array}$ & $\begin{array}{c}\text { Respiratory diseases, } \\
\text { cardiovascular diseases, } \\
\text { urinary diseases, and } \\
\text { organophosphorus poisoning }\end{array}$ & 54 & $1-18$ & Lecture & $8-16$ & $\begin{array}{c}\text { Bedside } \\
\text { teaching, case } \\
\text { discussion, and } \\
\text { teaching rounds }\end{array}$ \\
\hline Part II & $\begin{array}{l}2019.9 \\
\sim 2020.1\end{array}$ & $\begin{array}{c}\text { Digestive diseases, } \\
\text { haematological diseases, } \\
\text { endocrine diseases, and } \\
\text { rheumatology diseases }\end{array}$ & 54 & $1-18$ & Lecture & $8-15$ & $\begin{array}{c}\text { Bedside } \\
\text { teaching, case } \\
\text { discussion, and } \\
\text { teaching rounds }\end{array}$ \\
\hline
\end{tabular}


The contents of internal medicine included aetiology, pathogenesis, clinical manifestations, laboratory tests, diagnosis, and differential diagnosis and treatment principles. As shown in Table 1, the course was divided into part I and part II. Each part contained theoretical learning and practical training. The theoretical part was taught in class. In the practical teaching process, students were divided into small groups, with 4-5 students in a group. The training process was completed in a ward, students interviewed real patients and learned how to collect clinical data, how to analyse these data and how to make diagnosis and treatment plans. The modes included bedside teaching, case discussions and teaching rounds. In the practical part, students were trained to solve clinical problems and develop clinical reasoning skills by using basic clinical skills, such as gathering history and performing a physical examination.

\subsection{Study Design}

In this study, all cases were finished as homework. From the $1^{\text {st }}$ week to the $3^{\text {rd }}$ week, cases were collected and edited. In the 4th week, the teacher introduced relevant contents to the students, such as the definition of clinical reasoning and learning tasks, and demonstrated the reasoning procedure through a case. Starting in the 5th week, cases were sent to students through the Rain Classroom e-learning platform. Students were required to complete and submit their answers within three days so that they would have enough time to review and analyse the cases. The teacher corrected these answers in the Rain Classroom platform. Feedback was individually given to the students. The study design was shown in Figure 1.

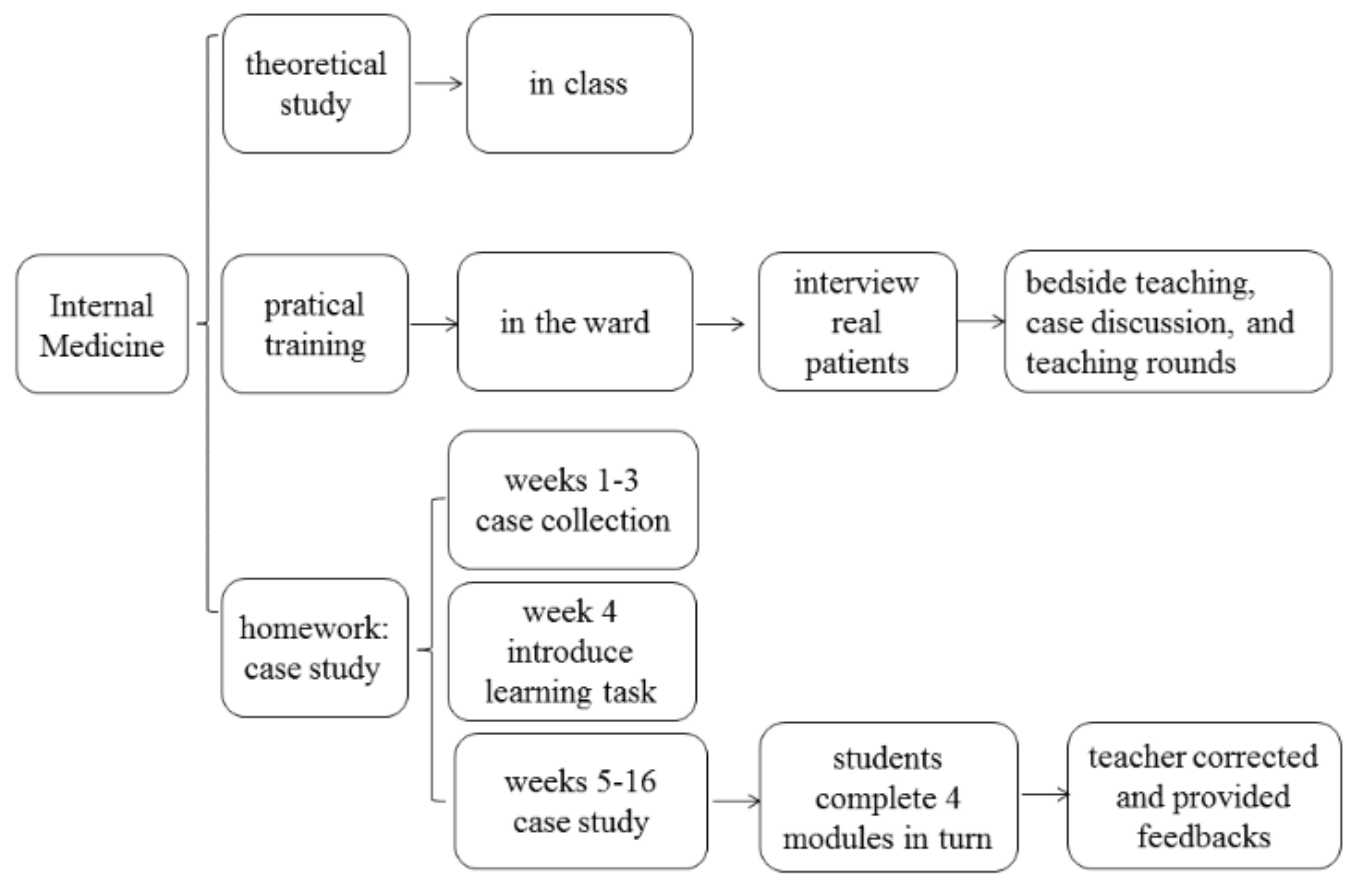

Figure 1. Flowchart of the Study Design

\subsection{Case Information}

The cases were numbered 1, 2, 3, etc. According to the diagnosis and therapeutic procedures, every case was divided into four modules: module one focused on inquiry, module two focused on physical examination, module three focused on laboratory tests and module four focused on diagnosis and treatment; 1, 2, 3 and 4 were used to express these modules, respectively. The contents and objectives of each module are shown in Figure 2. An example case in this study is shown in Table 2, the diagnosis of this case is acute pancreatitis. 


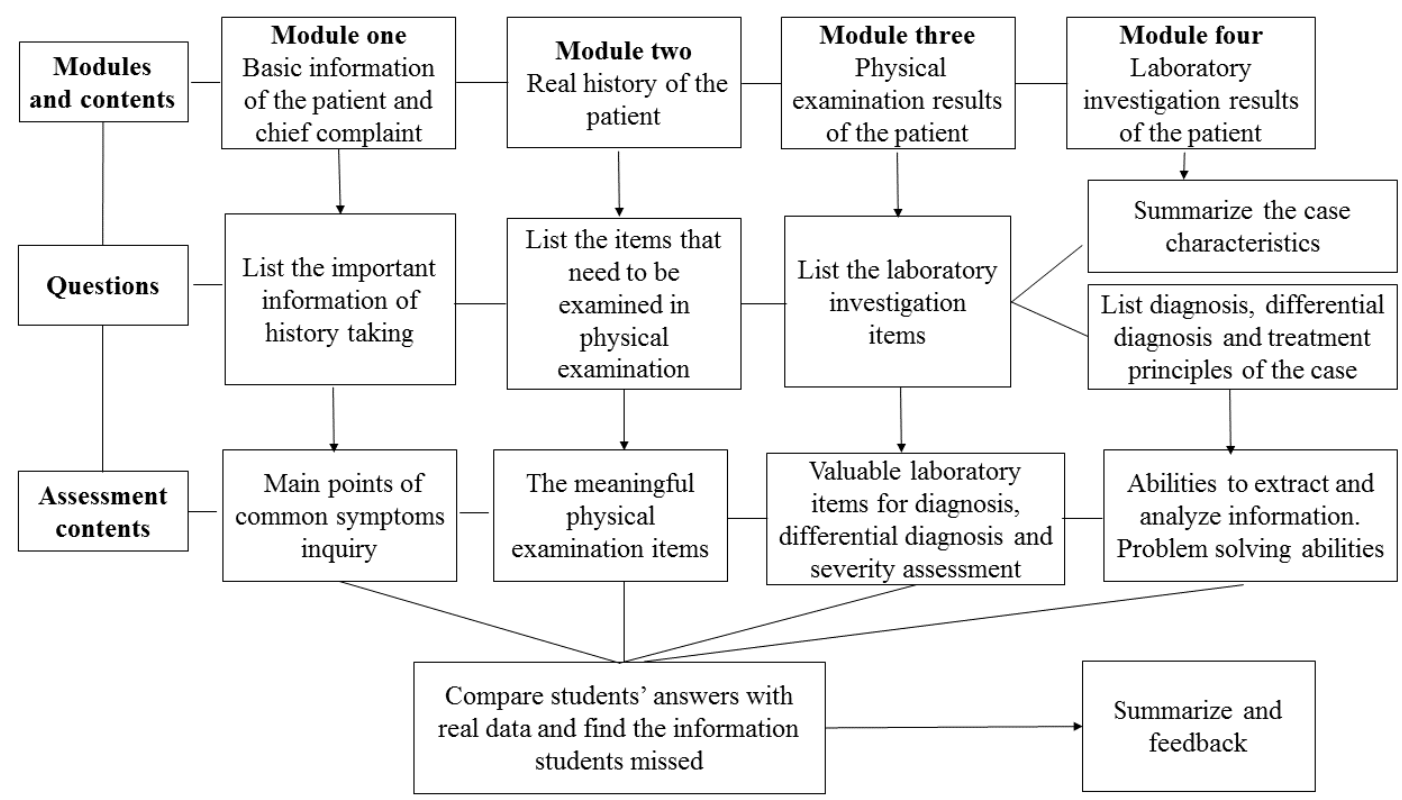

Figure 2. Contents and Objectives of Each Module

Table 2. A Case of Acute Pancreatitis

\begin{tabular}{ll}
\hline \multicolumn{1}{c}{ Modules and contents } & \multicolumn{1}{c}{ Questions } \\
\hline & $\begin{array}{l}\text { Question one } \\
\text { List the important } \\
\text { patient history }\end{array}$ \\
A 63-year-old man was admitted complaining of 14 hours of abdominal pain. & $\begin{array}{l}\text { information } \\
\text { according to the } \\
\text { chief complaint. }\end{array}$
\end{tabular}

Module two

History of the present illness: The patient complained of pain in the middle and upper abdomen after drinking and eating a heavy meal 14 hours ago. The pain is persistent and gradually aggravating, radiating to the back, with a fever (temperature unknown), abdominal distention, nausea, and vomiting two times with gastric contents. There is no hematemesis. After an intramuscular injection of "654-2" in the community hospital, the abdominal pain did not subside. Therefore, he sought medical attention. Since the onset of the disease, the patient did not eat anything, had a yellow thin stool 1 time, normal urine, and no appreciable recent weight change.

Past history: He experienced right epigastric pain around 3 years ago. At that time, it was found via an ultrasound that he had cholecystitis and a gallbladder stone. He has a 5 year history of hypertension. Usually, he takes "Lotensin" to control his blood pressure.

He is married and has two children. He denies using any other medications, tobacco, and alcohol.

Question two

List the items that need to be examined during the physical examination according to the patient's history. 
Module three

Upon examination, temperature is $38.0^{\circ} \mathrm{C}$, pulse is $104 \mathrm{bpm}$, respiration rate is $20 \mathrm{bpm}$, and blood pressure is $160 / 100 \mathrm{mmHg}$. The patient has normal development, overnutrition, and is overweight. The patient's expression is painful, and he is in a crouched body position. He is conscious and physically cooperative. His skin and sclera are without jaundice. He has no rales in both lungs. His heart rate is $104 \mathrm{bpm}$, with no irregular rhythm. He has no heart murmur. His abdomen is soft and epigastric, and the right upper quadrant has tenderness to palpation and no rebound tenderness. Murphy's sign is negative. The liver and spleen are not palpated. Shifting dullness is negative. There are hypoactive bowel sounds with $2 \sim 3 \mathrm{bpm}$. No masses or organomegaly are detected. There is no oedema in the lower limbs.

Module Four

Laboratory tests

Routine blood test: WBC, $14.3 \times 10^{9} / \mathrm{L} ; \mathrm{N}, 80.8 \%$, L, $12.2 \%$; Hb, $123 \mathrm{~g} / \mathrm{L}$; and Plt $233 \times 10^{9} / \mathrm{L}$

Biochemical test: Amylase, 525 U/L; ALT, 77.8 U/L; AST, 40.8 U/L; ALP, 184 U/L; GGT, 747 U/L; TBIL, 27.2 umol/L; DBIL, 4.5 umol/L; TG, $2.53 \mathrm{mmol} / \mathrm{L}$; blood glucose, 5.73 $\mathrm{mmol} / \mathrm{L}$; serum potassium, $4.74 \mathrm{mmol} / \mathrm{L}$; blood calcium, $2.16 \mathrm{mmol} / \mathrm{L}$; urea, $3.15 \mathrm{mmol} / \mathrm{L}$; $\mathrm{Cr}, 60 \mathrm{umol} / \mathrm{L} ; \mathrm{LDH}, 240 \mathrm{U} / \mathrm{L}$; and CK, $180 \mathrm{U} / \mathrm{L}$.

ECG: sinus rhythm. Normal ECG.

Plain abdominal radiograph: No free gas was observed below the diaphragm.

Ultrasound: gallbladder stone and cholecystitis. Pancreas not clearly shown due to gas. The liver, spleen, and kidneys are normal.

Question three

According to the patient's medical history and physical examination results, list the laboratory investigation items.

Upper abdominal CT (plain scan and enhancement): The pancreas is enlarged in size with rough margins and a uniform density after enhancement.

Abbreviations: White blood cell (WBC), Neutrophil (N), Lymphocyte (L), Haemoglobin (Hb).

Platelet (Plt), Alanine aminotransferase (ALT), Aspartic transaminase (AST), Alkaline phosphatase (ALP), $\gamma$-glutamyl transferase (GGT), Total bilirubin (TBIL), Direct bilirubin (DBIL), Triglyceride (TG), Creatinine (Cr), Lactic dehydrogenase (LDH), and Creatine kinase (CK). Electrocardiograph (ECG).

\subsection{Assessment Method}

A questionnaire was sent to students to evaluate the effect and students' perceptions about this training mode when the course as ended in January 2020. There were 10 questions. Each question had five choices: strongly agree (5 points), agree (4 points), neutral ( 3 points), disagree ( 2 points) and strongly disagree (1 point). The details of the questionnaire survey are shown in Table 3.

\subsection{Statistical Analysis}

The data were analysed using the SPSS 21.0 software. Quantitative data are expressed as the mean \pm standard deviation $(\mathrm{M} \pm \mathrm{SD})$.

\section{Results}

\subsection{Basic Data about the Cases}

Forty-seven students, including 28 males and 19 females, in grade 2015 participated this study. In the first semester, 6 cases were finished and included community-acquired pneumonia, chronic obstructive pulmonary disease, acute ST-segment elevation myocardial infarction, hypertension, nephrotic syndrome, and chronic renal failure (uraemia). In the second semester, the 5 cases that were finished included acute pancreatitis, upper gastrointestinal haemorrhage (peptic ulcer), diabetes mellitus, hyperthyroidism, and acute leukaemia. The homework arrangement and scores are shown in Figure 3 and Figure 4, respectively. 


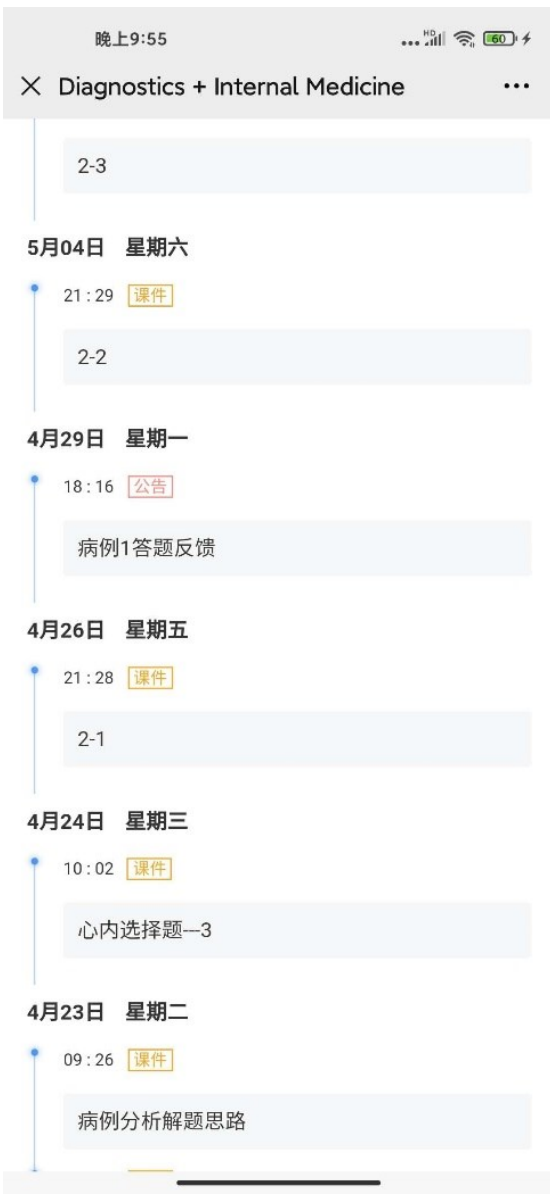

Figure 3. Homework for Students

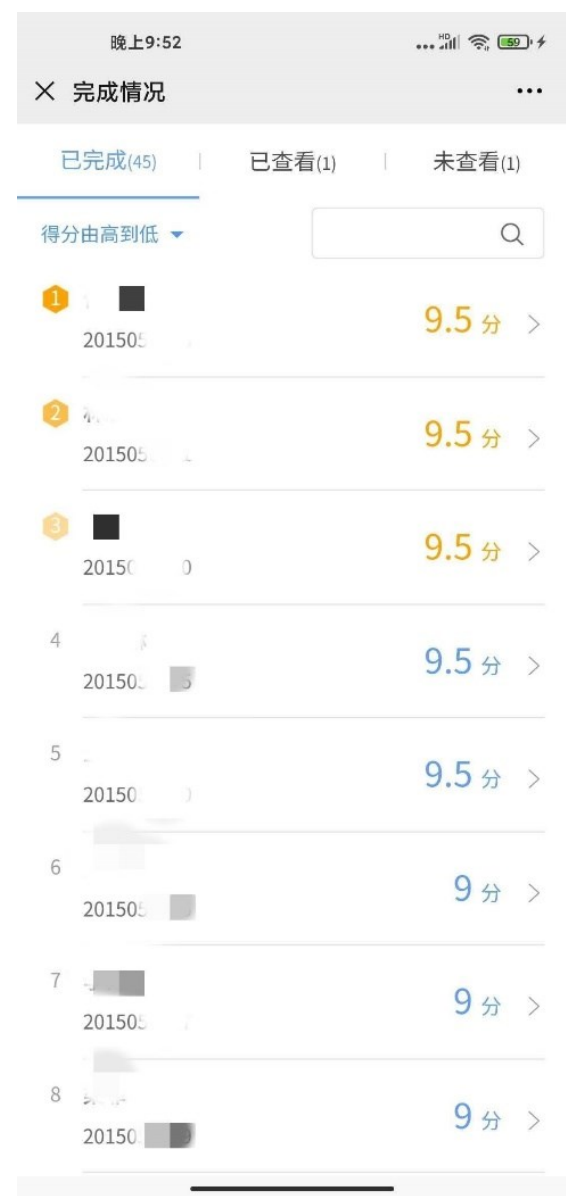

Figure 4. Homework Scores

\subsection{Questionnaire Results}

Table 3. Contents and Results of the Questionnaire Survey

\begin{tabular}{lc}
\hline \multicolumn{1}{c}{ Contents } & Results \\
\hline $\begin{array}{l}\text { 1. The mode of the step-by-step presentation of case information was helpful for improving } \\
\text { clinical reasoning ability. }\end{array}$ & $4.17 \pm 0.761$ \\
2. The mode of the step-by-step presentation of case information was helpful for understanding & $4.26 \pm 0.530$ \\
the diagnostic steps for diseases. & \\
3. The mode of the step-by-step presentation of case information was helpful for consolidating & $4.13 \pm 0.647$ \\
history taking and physical examination skills. & \\
4. The mode of the step-by-step presentation of case information was helpful for learning & $4.00 \pm 0.659$ \\
about routine laboratory items for diseases. & \\
5. The mode of the step-by-step presentation of case information was helpful for understanding & $4.00 \pm 0.659$ \\
of diseases' characteristics. & $4.11 \pm 0.667$ \\
6. The mode was helpful for understanding the therapeutic principles of common diseases. \\
7. The mode for presenting case information used in the course is an interesting mode. \\
8. The mode of the step-by-step presentation of case information was helpful for increasing & $3.98 \pm 0.74 \pm 0.736$ \\
interest in studying internal medicine. & \\
9. This method of presenting cases was helpful for increasing students' learning motivation. & $3.94 \pm 0.704$ \\
10. I would like to experience this training mode in the future. & $4.11 \pm 0.729$
\end{tabular}


All the students completed the questionnaire. As shown in Table 3, students were satisfied with this training mode. They thought the mode was helpful for improving clinical reasoning ability. It helped students understand the diagnostic steps and consolidate the basic skills such as history taking and physical examination. And they were willing to receive such training in the future.

\section{Discussion}

In this study, we sought to find a feasible mode to develop the clinical reasoning skills of undergraduate students, especially novices. In the clinical internal medicine course, a method for the step-by-step presentation of case information was introduced to fourth-year clinical medicine students. On the basis of theoretical and practical studies, cases were provided as homework to cultivate students' clinical reasoning skills. All the cases were designed as standardized questions. Each case contained four modules, which included patient history taking, physical examination, laboratory investigations and summarizing the case characteristics, diagnosis, differential diagnosis, and treatment plan. This training mode started with patient history taking, which is a key clinical skill for medical students. In this part, students needed to review the aetiology of common symptoms and then answer questions. This procedure is consistent with clinical practice in which clinical reasoning begins with the collection of a patient's medical history. Then, we focused on physical examination and laboratory investigations. All these steps sought to improve students' ability to gather information and analyse clinical data. Next, students were required to make diagnosis and treatment plans. These procedures train their abilities to combine theoretical knowledge and solve problems and can help students who are beginning to study clinical courses to develop scientific clinical reasoning skills. Li and collaborators proposed that comprehensive evidence collected in the early phase of clinical reasoning helped students make correct diagnoses (Li, Zheng \& Lajoie 2020).

There is no shortcut to develop clinical reasoning skills. These skills take time to accumulate, and they need guidance from teachers. Research shows that the training of clinical reasoning skills received in undergraduate education plays a key role in improving diagnostic accuracy and reducing misdiagnoses (Rencic, Trowbridge, Fagan, Szauter \& Durning 2017). It is important to develop students' clinical reasoning skills when they study clinical courses. In addition to the theory, the practical part is a very critical process for students to develop clinical reasoning. Students improve their clinical reasoning skills by interviewing and examining real patients. Through analysing patients' diagnoses and treatments, they learn how to analyse clinical problems.

Clinical reasoning is a core ability for a doctor, but assessing the process and results of this ability is still difficult (Boushehri, Kamran \& Arabshahi 2019). There are still no uniform indexes and standards for the assessment of clinical reasoning skills. The most common method is multiple choice questions (MCQs), and they are even considered to be the "gold standard" (Durning et al., 2015; Freiwald, Salimi, Khaljani \& Harendza 2014). In addition to MCQs, open short questions and concept map construction are also used to evaluate clinical reasoning ability (Radwan, Nasser, Araby \& Talaat 2018; Boulouffe, Charlin \& Vanpee 2010). In a study conducted by Harendza et al., a questionnaire that included eight key skills of clinical reasoning was used to evaluate the effectiveness of learning clinical reasoning (Harendza, Krenz, Klinge, Wendt \& Janneck 2017). These skills included summarizing a complex case with a brief sentence, requesting laboratory tests based on hypotheses and assessing the tests correctly, listing differential diagnoses, and others. Moreover, the script concordance test (SCT) is a reliable and effective way to evaluate clinical reasoning (Boulouffe, Charlin \& Vanpee 2010; Marie et al., 2005; Ruiz et al., 2010). In this study, a questionnaire was used to assess the benefits of this teaching mode. Students generally commented that this mode deepened their understanding of the process of diagnosing diseases. This mode can consolidate basic skills, such as patient history taking and physical examination. This mode allowed students to think when analysing the results of investigations and improve their problem solving ability. Clearly, the development of clinical reasoning ability is a long-term process that needs time to accumulate. Some methods may have a long-term impact. Therefore, the effectiveness of a method may not be able to be judged by the results of one or two tests. Learning outcomes needs to be tracked, including students' abilities to interview patients and address problems during internships, even when becoming a doctor. Regarding this study, the effectiveness and influence of this method can be comprehensively judged in the future using students' performances in their internships and their scores on graduation exams.

There are some limitations to this study. First, only a single method was used to evaluate the learning effect. We did not provide scenarios to students to assess the learning effect because of the limited resources of teachers. It takes a considerable amount of time for each student to finish a complete patient reception and develop a diagnosis and treatment plan. In the research of $\mathrm{Li}$ et al., students finished two case diagnoses in approximately 90 minutes $(\mathrm{Li}$, Zheng \& Lajoie 2020). We did not have enough time to conduct this process because there are 47 students in one 
class. It may take approximately 40 minutes to finish the procedure for interviewing a patient and making a decision. Therefore, we did not design scenarios for students to interview a standardized patient or real patients. Some scholars believe that many factors, such as patients, cooperation and contextual factors, can affect the results of clinical reasoning (McBee et al., 2017; Durning et al., 2012; McBee et al., 2015). In reality, the actual clinical environment is complex, and it is difficult to fully simulate the clinical reasoning process. Second, the examination scores were not shown and compared with those of previous students. Our final exam included definitions, fill-in-the-blank questions, short answer questions, MCQs and case analysis. The first three contents are mainly based on memory. Although the proportion of the MCQs and case analysis questions accounted for $60 \%$ of the total, some MCQs were still mainly memorized, which cannot fully reflect the clinical reasoning and thinking process. In addition, the teacher knows the students' reasoning processes and results mainly based on their assignments. Different from face-to-face discussions, this process lacks communication between the teacher and students. Some researchers think that mastering students' thinking processes and quickly identifying students' learning styles can help teachers adjust teaching strategies and objectives (Pottier et al., 2010).

Based on our teaching experience and the literature review, the ideal model for developing clinical reasoning skills for medical students should include the following steps. First, in the medical education stage, courses can be designed to help students develop clinical reasoning skills. A survey on a clinical reasoning curriculum conducted by Andrzej et al. revealed that a clinical reasoning curriculum was reported by only $28 \%$ of the respondents, and $85 \%$ stated that such a curriculum was needed (Kononowicz et al., 2020). Through these curricula, students can master the concepts and relevant knowledge of clinical reasoning. In fact, a new clinical reasoning curriculum can improve medical students' clinical reasoning ability. A study conducted in second year medical students who participated in a clinical reasoning curriculum that included three sections of case studies assessed the learning effect of students who interviewed a standardized patient. The results showed that the curriculum improved students' reasoning ability (Kelekar \& Afonso 2020). Another study also showed the effectiveness of developing a clinical reasoning course for medical students (Harendza, Krenz, Klinge, Wendt \& Janneck 2017). Second, faculty training can change teachers' education ideas and teaching methods and improve their teaching abilities. The lack of experienced teachers is another obstacle to the development of clinical reasoning courses. Medical students have mastered the necessary knowledge required for making diagnoses through theoretical studies, but they do not know how to integrate and apply this knowledge in clinical practical problems. With effective guidance from teachers, students can develop reasoning skills more quickly. Third, appropriate teaching strategies and evaluation methods should be adopted according to the specific situation. There are many effective methods to teach and assess clinical reasoning. We need to choose appropriate methods according to the grade of students, teachers and other factors. In fact, it takes time to cultivate and improve reasoning ability. This skill needs to be accumulated in practice through contact with real patients.

\section{Conclusion}

Clinical reasoning ability is one of the core abilities in cultivation of medical students. Clinical practice and scientific reasoning skills are the two major factors of clinical reasoning. The process of clinical reasoning begins from history taking and continues until a diagnosis is made. Many methods are offered to develop clinical reasoning skills. Practice with cases is a very common choice. In our practice, the mode for the step-by-step presentation of case information provides a training method for developing the clinical reasoning ability of medical students. Through the process of analysing clinical cases, students are guided to become familiar with the procedures of solving clinical problems from gathering medical information to establishing diagnosis and treatment plans. It helps students to establish a correct clinical reasoning mode. The training method also let students realize the importance of basic clinical skills such as history taking and physical examination, so as to continue to strengthen and consolidate these basic skills in the future. But the assessment method for this new mode can be improved and optimized in the future to evaluate the learning effect scientifically. Clinical scenes should be set up for assessment. In addition, tracking students' performance in internship and scores of objective structured clinical examination (OSCE) in graduation examination is another approach to evaluate the long-term effect of this mode.

\section{Acknowledgements}

The authors would like to thank all of the teachers from different specialties in internal medicine and the medical students who participated in this study. 


\section{Funding source}

This study was supported by education reform projects of Jinan University (grant number: JNU-J-CXGC2018003; JG2019013; JG2019044; JG2019127).

\section{References}

Audétat, M. C., Dory, V., Nendaz, M., Vanpee, D., Pestiaux, D., Junod Perron, N., \& Charlin, B. (2012). What is so difficult about managing clinical reasoning difficulties? Medical Education, 46(2), 216-227. https://doi.org/10.1111/j.1365-2923.2011.04151

Beullens, J., Struyf, E., \& Damme, B. V. (2005). Do extended matching multiple-choice questions measure clinical reasoning? Medical Education, 39(4), 410-417. https://doi.org/10.1111/j.1365-2929.2005.02089.x

Botezatu, M., Hult, H., \& Fors, U. G. (2010). Virtual patient simulation: what do students make of it? A focus group study. BMC Medical Education, 10, 91. https://doi.org/10.1186/1472-6920-10-91

Boulouffe, C., Charlin, B., \& Vanpee, D. (2010). Evaluation of clinical reasoning in basic emergencies using a script concordance test. American Journal of Pharmaceutical Education, 74(10), 194. https://doi.org/10.5688/aj7410194

Bediang, G., Franck, C., Raetzo, M. A., Doell, J., Ba, M., Kamga, Y., Baroz, F., \& Geissbuhler, A. (2013). Developing Clinical Skills Using a Virtual Patient Simulator in a Resource-Limited Setting. Studies in Health Technology and Informatics, 192, 102-106. https://doi.org/10.3233/978-1-61499-289-9-102

Berge, K.V. D., \& Mamede, S. (2013). Cognitive diagnostic error in internal medicine. European Journal of Internal Medicine, 24(6), 525-529. https://doi.org/10.1016/j.ejim.2013.03.006

Boushehri, E., Kamran, A. M., \& Arabshahi, S. (2019). Key feature, clinical reasoning problem. Puzzle and scenario writing: Are there any differences between them in evaluating clinical reasoning? Trends in Medicine, 19, 1-7. https://doi.org/10.15761/TiM.1000188

Durning, S. J., Artino, A. R., Boulet, J. R., Dorrance, K., Vleuten, C. V. D., \& Schuwirth, L. (2012). The impact of selected contextual factors on experts' clinical reasoning performance (does context impact clinical reasoning performance in experts?). Advances in Health Sciencese Education, 17(1), 65-79. https://doi.org/10.1007/s10459-011-9294-3

Deng, Y. L., \& Liu, S. J. (2015). Review of research on clinical reasoning theory. Chinese Journal of Diagnostics (Electronic Edition), 3(2), 86-89. https://doi.org/10.3877/cma.j.issn.2095-655X.2015.02.003

Dong, T., Durning, S. J., Artino Jr, A. R., der Vleuten, C. V., Holmboe, E., Lipner, R., \& Schuwirth, L. (2015). Dual process theory and intermediate effect: are faculty and residents' performance on multiple-choice, licensing exam questions different? Military Medicine, 180(4), 92-96. https://doi.org/10.7205/MILMED-D-14-00555

Durning, S. J., Costanzo, M. E., Artino, A. R., Graner, J., Vleuten, C. V. D., Beckman, T. J., Wittich, C. M., Roy, M. J., Holmboe, E. S., \& Schuwirth, L. (2015). Neural basis of nonanalytical reasoning expertise during clinical evaluation. Brain and Behavior, 5(3), e00309. https://doi.org/10.1002/brb3.309

Daly, P. (2018). A concise guide to clinical reasoning. Journal of Evaluation in Clinical Practice, $24(5), 966-972$. https://doi.org/10.1111/jep.12940

Elvén, M., Hochwälder, J., Dean, E., \& Söderlund, A. (2019). Predictors of clinical reasoning using the reasoning 4 change instrument with physical therapist students. Physical Therapy, 99(8), 964-976. https://doi.org/10.1093/ptj/pzz044

Freiwald, T., Salimi, M., Khaljani, E., \& Harendza, S. (2014). Pattern recognition as a concept for multiplechoice questions in a national licensing exam. BMC Medical Education, $14, \quad 232$. https://doi.org/10.1186/1472-6920-14-232

Goldmann, M., Middeke, A. C., Schuelper, N., Dehl, T., \& Raupach, T. (2017). Choosing wisely in medical education. Z. Evid. Fortbild. Qual. Gesundh. wesen, 129, 22-26. https://doi.org/10.1016/j.zefq.2017.10.014

Harendza, S., Krenz, I., Klinge, A., Wendt, U., \& Janneck, M. (2017). Implementation of a clinical reasoning course in the internal medicine trimester of the final year of undergraduate medical training and its effect on students' case presentation and differential diagnostic skills. GMS Journal for Medical Education, 34(5), Doc66. https://doi.org/10.3205/zma001143 
Kim, S., Willett, L. R., Pan, W. J., Afran, J., Walker, J. A., \& Shea, J. A. (2018). Impact of required versus self-directed use of virtual patient cases on clerkship performance: A mixed-methods study. Academic Medicine, 93(5), 742-749. https://doi.org/10.1097/ACM.0000000000001961

Kelekar, A., \& Afonso, N. (2020). Evaluation of the effect of a new clinical reasoning curriculum in a pre-clerkship clinical skills course. Perspect Med Educ, 9(2), 123-127. https://doi.org/10.1007/s40037-020-00566-4

Kononowicz, A. A., Hege, I., Edelbring, S., Sobocan, M., Huwendiek, S., \& Durning, S. J. (2020). The need for longitudinal clinical reasoning teaching and assessment: results of an international survey. Medical Teacher, 42(4), 457-462. https://doi.org/10.1080/0142159X.2019.1708293

Li, S., Zheng, J., \& Lajoie, S. P. (2020). Efficient clinical reasoning: Knowing when to start and when to stop. Education in the Health Professions, 3(1), 1-7. https://doi.org/10.4103/EHP.EHP_1_20

Marie, I., Sibert, L., Roussel, F., Hellot, M. F., Lechevallier, J., \& Weber, J. (2005). The script concordance test: a new evaluation method of both clinical reasoning and skills in internal medicine. La Revue De Médecine Interne, 26(6), 501-507. https://doi.org/10.1016/j.revmed.2004.10.028

McBee, E., Ratcliffe, T., Picho, K., Anthony R. Artino Jr, A. R., Schuwirth, L., Kelly, W., Masel, J., der Vleuten, C. V., \& Durning, S. J. (2015). Consequences of contextual factors on clinical reasoning in resident physicians. Advances in Health Sciences Education, 20(5), 1225-1236. https://doi.org/10.1007/s10459-015-9597-x

Musgrove, J. L., Morris, J., Estrada, C. A., \& Kraemer, R. R. (2016). Clinical reasoning terms included in clinical problem solving exercises? Journal of Graduate Medical Education, 8(2), 180-184. https://doi.org/10.4300/JGME-D-15-00411.1

McBee, E., Ratcliffe, T., Picho, K., Schuwirth, L., Jr, A. R. A., Yepes-Rios, A. M., Masel, J., Vleuten, C. V. D., \& Durning, S. J. (2017). Contextual factors and clinical reasoning: differences in diagnostic and therapeutic reasoning in board certified versus resident physicians. BMC Medical Education, 17(1), 211. https://doi.org/10.1186/s12909-017-1041-x

Monrouxe, L. V., Grundy, L., Mann, M., John, Z., Panagoulas, E., Bullock, A., \& Mattick, K. (2017). How prepared are UK medical graduates for practice? A rapid review of the literature 2009-2014. BMJ Open, 7(1), e013656. https://doi.org/10.1136/bmjopen-2016-013656

Mamede, S., Figueiredo-Soares, T., Santos, S. M. E., Faria, R. M. D., Schmidt, H. G., \& Gog, T. V. (2019). Fostering novice students' diagnostic ability: the value of guiding deliberate reflection. Medical Education, 53(6), 628-637. https://doi.org/10.1111/medu.13829

Pottier, P., Hardouin, J. B., Hodges, B. D., Pistorius, M. A., Connault, J., Durant, C., Clairand, R., Sebille, V., Barrier, J. H., \& Planchon, B. (2010). Teaching with cognition: exploring how students think: a new method combining think-aloud and concept mapping protocols. Medical Education, 44(9), 926-935. https://doi.org/10.1111/j.1365-2923.2010.03748.x

Ruiz, J. G., Tunuguntla, R., Charlin, B., Ouslander, J. G., Symes, S. N., Gagnon, R., Phancao, F., \& Roos, B. A. (2010). The script concordance test as a measure of clinical reasoning skills in geriatric urinary incontinence. Journal of the American Geriatrics Society, 58(11), 2178-2184. https://doi.org/10.1111/j.1532-5415.2010.03136.x

Rencic, J., Trowbridge Jr, R. L., Fagan, M., Szauter, K., \& Durning, S. (2017). Clinical reasoning education at us medical schools: results from a national survey of internal medicine clerkship directors. Journal of General Internal Medicine, 32(11), 1242-1246. https://doi.org/10.1007/s11606-017-4159-y

Radwan, A., Nasser, A. A., Araby, S. E., \& Talaat, W. (2018). Correlation between Assessment of Concept Maps Construction and the Clinical Reasoning Ability of Final Year Medical Students at the Faculty of Medicine. Suez Canal University, Egypt. Education in Medicine Journal, 10(4), 43-51. https://doi.org/10.21315/eimj2018.10.4.5

Sacher, A. G., \& Detsky, A. S. (2009). Taking the stress out of morning report: an analytic approach to the differential diagnosis. Journal of General Internal Medicine, 24(6), 747-751. https://doi.org/10.1007/s11606-009-0953-5

Shimozono, H., Takahashi, M., Tomita, M., Takada, K., \& Tanaka, Y. (2019). "The 2-Dimensional Approach": a novel tool to help learners organize their knowledge and improve their clinical reasoning skills. MedEdPublish, 8(2), 1-16. https://doi.org/10.15694/mep.2019.000134.1 
Shin, H. S. (2019). Reasoning processes in clinical reasoning: from the perspective of cognitive psychology. Korean Journal of Medical Education, 31(4), 299-308. https://doi.org/10.3946/kjme.2019.140

Yang, L. H., Jiang, L. Y., Xu, B., Liu, S. Q., Liang, Y. R., Ye, J. H., \& Tao, E. X. (2014). Evaluating team-based, lecture-based, and hybrid learning methods for neurology clerkship in China: a method-comparison study. BMC Medical Education, 14, 98. https://doi.org/10.1186/1472-6920-14-98

Yang, L. Y., Huang, C. C., Hsu, H. C., Yang, Y. Y., Chang, C. C., Chuang, C. L., Lee, W. S., Liang, J. F., Cheng, H. M., Huang, C. C., Lee, F. Y., Ho, S. T., \& Kirby, R. (2017). Voluntary attendance of small-group brainstorming tutoring courses intensify new clerk's "Excellence in Clinical Care": A pilot study. BMC Medical Education, 17(1), 2. https://doi.org/10.1186/s12909-016-0843-6

\section{Copyrights}

Copyright for this article is retained by the author(s), with first publication rights granted to the journal.

This is an open-access article distributed under the terms and conditions of the Creative Commons Attribution license (http://creativecommons.org/licenses/by/4.0/). 